
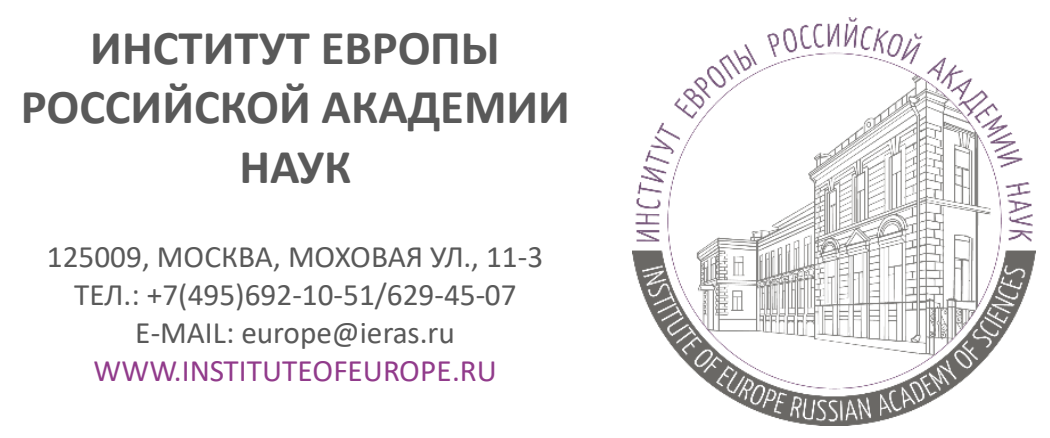

INSTITUTE OF EUROPE RUSSIAN ACADEMY OF SCIENCES

125009, MOSCOW, MOKHOVAYA STR., 11-3

TEL.: +7(495)692-10-51/629-45-07

E-MAIL: europe-ins@mail.ru

WWW.INSTITUTEOFEUROPE.RU

Серия «Аналитические записки Института Европы РАН»

№44, 2020 (№227)

\title{
Пограничный корректирующий углеродный механизм ЕС: статус, риски и возможный ответ
}

\author{
Анатолий Иванович Бажан \\ доктор экономических наук, руководитель Отдела экономических исследований \\ Института Европы РАН \\ Сергей Анатольевич Рогинко
}

кандидат экономических наук, руководитель Центра экологии и развития Института

Европы РАН, профессор Финансового Университета при Правительстве РФ

\begin{abstract}
Аннотация. Предмет анализа - инициатива EC по введению т.н. Пограничного корректирующего углеродного механизма, разработанного в рамках принятого в 2019 году «Европейского Зеленого курса». Авторами подробно разбирается генезис европейских инициатив в области пограничного углеродного налога, проводится параллель между Пограничным корректирующим углеродным механизмом и ранними инициативами ЕС по углеродному налогообложению рейсов зарубежных авиакомпаний, выполняемых в аэропорты стран ЕС. Дается описание тактики Евросоюза по разработке деталей предлагаемого механизма и продвижения его на международной арене. Особое внимание уделяется оиенке рисков российских экспортных отраслей в случае введения Пограничного корректирующего углеродного механизма и возможным ответным мерам с российской стороны.
\end{abstract}

DOI: http://doi.org/10.15211/analytics442020 
Ключевые слова: Пограничный корректирующиий углеродный механизм, «Европейский Зеленый курс», углеродная утечка, выбросы парниковых газов, Парижское согламение, Европейская система торговли выбросами, система CORSIA, климатическая нейтральность, стратегия регенеративного роста, План восстановления экономики ЕС после эпидемии коронавируса, «углеродный след» импортных товаров, Европейские разрешения на выбросы парниковых газов, углеродный бюджет, ВТО, Генеральное согламение по тарифам и торговле.

\section{История вопроса}

Идея пограничного углеродного налога не нова; её инициатором ещё 10 лет назад выступала Франция. Идею последовательно озвучивали президенты республики: Николя Саркози, Франсуа Олланд и Эммануэль Макрон. Последний проявляет в настоящее время особую активность. Именно благодаря усилиям Франции в тандеме с Нидерландами родилась современная версия пограничного налога в виде так называемого «Пограничного корректирующего углеродного механизма» (ПКУМ), который Еврокомиссия намерена внедрить в хозяйственную практику в ближайшей перспективе. Что касается Германии и особенно стран Восточной Европы, то их отношение к инициативе является более сдержанным.

Первая попытка использовать по существу пограничный налог была предпринята ЕС в 2012 г. В качестве зоны действия его применения был выбран сектор гражданской авиации; предполагалось, начиная с этого года, включить в Европейскую систему торговли выбросами парниковых газов (EU ETS) зарубежные авиакомпании, выполняющие рейсы в ЕС. Это означало, что такие компании были бы обязаны покупать европейские разрешения на выбросы (EU Allowances-EUA) за каждый полет, выполненный в европейский аэропорт, основываясь на существующих ценах на EUA. Причем предполагалось учитывать выбросы, которые имеют место за всё время полёта самолета, который приземляется в странах объединения или вылетает оттуда. Суммы расходов на покупку этих разрешений оценивались ассоциациями авиакомпаний более чем в 22,5 млрд долл. в период до 2020 г.

Действия ЕС по продвижению этой системы получения дохода заслуживают специального рассмотрения, поскольку показывают особенности стиля Еврокомиссии, с которым mutatis mutandis придется иметь дело и в нынешней ситуации с ПКУМ. Эти особенности сводятся к следующему.

1. Закрытый характер обсуждения и принятия решений внутри $\mathrm{EC}$, упорные попытки уйти от дискуссии с зарубежными партнерами по вопросам, их касающимся, вплоть до окончательного принятия решения и утверждения нормативов на уровне ЕС.

2. Неприятие любых попыток перенести дискуссию на международную площадку, включая площадки структур ООН.

3. В случае такого переноса - попытки затянуть дискуссию и далее прекратить ее по причине якобы бесполезности.

4. В случае судебного разбирательства, инициированного зарубежными оппонентами, блокирование любого разбирательства вне юрисдикции ЕС. 
5. В случае судебного разбирательства в юридических инстанциях ЕС, обязательное вынесение решений в пользу ЕС, невзирая на доводы оппонентов и на несоответствие этих решений здравому смыслу и международному праву.

6. Уступки оппонентам - только под колоссальным давлением и при наличии реальных угроз со стороны двух основных игроков - США и Китая.

7. При наличии уступок использование мер по «сохранению лица», представление уступок не в качестве результата ошибочных действий ЕС, а как временных действий в рамках общей правильной политики Евросоюза.

Всю эту тактику Евросоюз продемонстрировал в ходе продвижения «авиационного углеродного налога»: тут было и одностороннее распределение лимитов выбросов в тоннах CO2 на 2012 и 2013 гг. между зарубежными авиакомпаниями (без согласования с этими компаниями). И абсурдные возражения Евросоюза о том, что вводится не экстерриториальный налог, а рыночный механизм, который не является налогом. И разбирательство в Европейском суде, инициированное авиакомпаниями США, которое не принесло позитивных для авиакомпаний результатов, несмотря на противоречие позиции ЕС Чикагской конвенции и правилам ВТО. В постановлении Европейского суда говорилось, что ЕС имеет право навязать эту схему коммерческим авиакомпаниям, которые предпочитают работать в европейских аэропортах и, таким образом, подпадают под юрисдикцию ЕС. Доводы о том, что навязывание Евросоюзом платежей за полеты в европейские аэропорты и обратно нарушает национальный суверенитет, были отвергнуты.

Странам-оппонентам налога стало ясно, что Евросоюз зашел слишком далеко, и остановить его могут только а) жесткие меры б) скоординированные действия. Здесь проявила инициативу Россия, проведшая двухдневную встречу противников инициативы ЕС в Москве. По итогам встречи представители 26 стран, договорились об ответных мерах, которые выразились в том, что:

- обе палаты Конгресса США приняли закон, запрещающий авиакомпаниям США платить Европейскому Союзу за свои авиационные выбросы СО2;

- Китай, в дополнение к своим заявлениям о неприятии инициативы ЕС, заблокировал заказ на покупку самолетов у компании Airbus;

- Индия намекнула на то, что европейские перевозчики могут столкнуться с ограничениями на полеты в эту страну;

- Россия дала понять, что могла бы возобновить для европейских авиакомпаний сборы за полеты через Сибирь, которые ранее были отменены.

Оппоненты европейского подхода нашли и подходящую профильную площадку для нового судебного разбирательства в организациях ООН. Такой площадкой была выбрана система разрешения споров в Международной организации гражданской авиации (ИКАО). Поскольку американское доминирование в системе ИКАО ни для кого не является секретом, перспектива подобного разбирательства для ЕС выглядела заведомо провальной.

Все эти меры изменили ситуацию и побудили некоторые правительства стран ЕС усомниться в разумности действий Еврокомиссии. В частности, вопрос о возможности 
отсрочки или корректировки реализации схемы платежей был поднят правительствами Италии и Нидерландов. Еврокомиссия оказалась вынужденной дать обратный ход и скорректировать меры, обозначив этот шаг как временную отсрочку. В итоге вопрос о системе углеродной торговли для авиационного сектора был передан на интернациональный уровень - в ИКАО, где эта система (CORSIA) находится в стадии доработки с предполагаемым сроком запуска в полном объеме лишь в 2027 г.

\section{Текущая ситуация}

Новая перспектива для трансграничного углеродного налога возникла в декабре 2019 г., когда Европейская комиссия презентовала «Европейский зеленый курс» (European Green Deal), в соответствии с которым рассматривается возможность введения «пограничного корректирующего углеродного механизма». Сам «Европейский зеленый курс» рассчитан на достижение Евросоюзом к 2050 г. климатической нейтральности и преподносится как «новая стратегия регенеративного роста», не требующего добычи природных ископаемых. На достижение цели климатической нейтральности только из бюджета ЕС предусматриваются расходы в размере 1 трлн евро в ближайшее десятилетие при общем планируемом размере инвестиций в 2,6 трлн евро.

В озвученном 16 сентября 2020 г. председателем Еврокомиссии Урсулой фон дер Ляйен послании под названием «Состояние Союза» (EU State of the Union, 2020) поставлены более амбициозные задачи. В этом послании сформулирована новая цель по сокращению выбросов парниковых газов к 2030 г. Вместо официально зафиксированной по линии Парижского соглашения обязательства снизить выбросы на 40\% по отношению к 1990 г. ЕС намечает их сокращение на 55\%.

Эту цель Еврокомиссия планировала закрепить в 2020 г. на законодательном уровне и использовать в качестве основы пересмотра в июне 2021 г. всех политических инструментов, связанных с климатической тематикой. В частности, в плане предполагается пересмотр параметров системы торговли квотами на выбросы парниковых газов (ETS) и распространения ее действия на новые секторы хозяйства (транспорт и ЖКХ).

Однако всё изменили результаты прошедшего 6 октября 2020 г. голосования в Европарламенте. Они показали приверженность евродепутатов еще более амбициозным целям. В итоге с небольшим отрывом (352 голоса против 326, при 18 воздержавшихся) была утверждена цель сокращения выбросов к 2030 г. на 60\% по отношению к 1990 г.

Окончательное утверждение нового ориентира - в компетенции Совета министров ЕС. Данная процедура не обещает быть легкой, особенно если вспомнить, с каким трудом удалось согласовать в декабре 2019 г. предыдущую установку (на сокращение выбросов на 55\%). Тогда Германия, Франция и другие сторонники повышения планки приложили немало усилий (и пообещали существенное финансирование), чтобы получить согласие от Польши, Чехии и Венгрии, собиравшихся заблокировать эту инициативу. Тем не менее, Еврокомиссия надеется завершить переговоры до конца нынешнего года. 
Инструментом сокращения выбросов парниковых газов служит повышение цены на эти выбросы. С этим связаны и аргументы ЕС, стремящегося ввести «Пограничный корректирующий углеродный механизм» (ПКУМ). Один из аргументов сформулирован в главном документе ЕС по «Европейскому зеленому курсу» - Сообщении Европейской комиссии «СОМ(2019) 640 final» от 11 декабря 2019 г. В нём говорится об «углеродной утечке» (Carbon Leakage), которая означает, что с увеличением цены на выбросы углерода в рамках Европейской системы торговли выбросами (EU ETS) финансовое давление на компании реального сектора принуждает их перемещать энергоёмкие производства в страны, где предприятия свободны от подобного обременения. А это приводит к увеличению выбросов вне ЕС, что, однако, по нашему мнению, плохо подтверждается фактами, которые говорят о том, что:

- перемещение предприятий энергоемких отраслей европейскими компаниями в основном завершилась 10-20 лет назад;

- эта релокация была вызвана, прежде всего, соображениями экономии на рабочей силе и на чисто природоохранных мероприятиях, к парниковым газам отношения не имеющим;

- в итоге экономика ЕС в основном уже перестроилась: потребляемая в ЕС энергоемкая продукция по большей части импортируется;

- именно этим переходом объясняется высокая энергоэффективность экономики стран ЕС по сравнению, в частности, с российской, в структуре которой преобладают энергоемкие отрасли; такое разделение труда делает экономики России и ЕС взаимно дополняющими;

- перспектива дальнейшего масштабного перемещения предприятий энергоемких отраслей не просматривается; более того, ЕС делает акцент именно на сохранении оставшихся энергоемких производств: в частности, в упомянутом документе «ЕС $\operatorname{COM(2019)~} 640$ final» читаем: «Энергоёмкие отрасли, такие как сталь, химикаты и цемент, необходимы для европейской экономики».

Очевидные факты не мешают чиновникам ЕС активно пользоваться соображениями о Carbon Leakage в ходе продвижения инициативы ПКУМ, которая, по их мнению, будет способствовать оздоровлению земной атмосферы.

Еще одна трактовка понятия «углеродной утечки» была презентована на Давосском форуме в январе 2020 г. в речи Урсулы фон дер Ляйен. По ее словам, «нет смысла только в сокращении парниковых газов у себя дома, если мы увеличиваем импорт парниковых газов из-за границы». Кроме того, как утверждает фон дер Ляйен, новый механизм призван решить не только климатические проблемы, но и в вопросы «справедливости» по отношению к бизнесу в странах ЕС; предполагается, что ПКУМ «защитит их от несправедливой конкуренции». Определённая логика в этих рассуждениях, конечно, есть. Но у неё есть и недостаток, ибо навязываемый странам, не входящим в ЕС, ПКУМ не может быть легитимным, если он противоречит международному праву, регулируемому в данной области Парижским соглашением по климату, главную роль которого признает и обязуется обеспечивать Евросоюз, о чём сказано в документе «ЕC COM(2019) 640 final». 
ПКУМ противоречит Парижскому соглашению в связи со следующими обстоятельствами:

- в рамках Соглашения каждая страна имеет право выбирать меры климатической политики в соответствии со своими обязательствами по Соглашению и особенностью экономической ситуации;

- до тех пор, пока страны соблюдают свои обязательства по линии Соглашения, любые условия торговли не могут корректироваться в целях заставить какую-либо сторону нести дополнительные расходы на оздоровление климата, в том числе и в связи с «углеродным следом» торгуемой продукции.

Если об этом помнить, то попытку ЕС «уравнять» с другими странами расходы, связанные с выбросами парниковых газов, нельзя рассматривать иначе как нарушение международного права и международных договоров, выражающееся в:

- попытке пересмотра Парижского соглашения, лишающей торговых партнеров ЕС легитимного права самостоятельного выбора стратегий и путей сокращения выбросов;

- экстерриториальной экспансии европейских правовых конструкций и норм углеродного регулирования, принудительно навязываемых другим странам в нарушение международного права.

Впрочем, есть еще одна озвученная в ЕС причина введения пограничного углеродного налога. Она состоит в желании финансово обеспечить выполнение плана восстановления экономики после эпидемии коронавируса (Next Generation EU Recovery Plan). ПКУМ рассматривается в качестве одного из источников финансирования мероприятий плана; по расчетам экспертов $\mathrm{EC}$, размер доходов от нового налога на импорт может составить от 5 млрд. евро до 14 млрд. евро в год, в зависимости от ставок налога и степени охвата товарных позиций импорта.

Поскольку такая откровенная постановка вопроса не прибавила ЕС популярности у его торговых партнеров; понимая это, фон дер Ляйен, адресуясь к оппонентам, намекнула на возможность при определённых условиях отмены ПКУМ в случае введения ими соответствующей внутренней цены на выбросы СО2. В адрес Китая прозвучал даже комплимент за первые шаги в данном направлении.

Однако, попытка «позолотить пилюлю» никого в Пекине не обманула: выступление фон дер Ляйен вызвало жесткую отповедь заместителя министра экологии и окружающей среды КНР Чжао Инминя, который заявил, что «страны должны предотвратить односторонность и протекционизм, чтобы они не повредили ожиданиям глобального роста».

Еще жестче была реакция Вашингтона: министр торговли США Уилбур Росс предупредил, что администрация Трампа ответит «мерами наказания» на планы Брюсселя по введению пограничного углеродного налога. Его коллега, министр финансов США Стив Мнучин предупредил, что «углеродный налог - это налог... на трудящихся» и озвучил одну из самых серьезных проблем, связанных с его введением: трудности с методологией расчета налоговой базы. 
Пока вразумительного ответа ЕС на эти заявления не прозвучало. Еврокомиссия сделала вид, как будто ничего не произошло, и бросила лучшие силы экспертов на разработку и продвижение налогового механизма. Урсула фон дер Ляйен продолжает настаивать на том, что ПКУМ будет введен в действие тогда и там, где он понадобится. Задаче продвижения механизма придан чрезвычайный статус. К её решению привлечен не только профильный первый вице-президент ЕК Франц Тиммерманс, но также все руководители Еврокомиссии, так или иначе причастные к теме, в том числе Еврокомиссар по торговле Фил Хоган, Еврокомиссар по экономике и финансам Паоло Джентилони, Еврокомиссар по энергетике Кадри Симсон и др. Эта VIP-команда должна обеспечить продвижение ПКУМ в соответствии с «Дорожной картой», которая предусматривает:

- налаживание обратной связи с заинтересованными сторонами (4 марта - 1 апреля 2020 г.);

- общественные консультации в ЕС (22 июля - 28 октября 2020 г.);

- принятие предложений Еврокомиссией (2-й квартал 2021 г.); представление согласованного документа в июне 2021 г.

Обращает внимание беспрецедентно короткий срок, отведенный на получение обратной связи от заинтересованных сторон (меньше месяца). Необычна для ЕС была и низкая степень проработанности новой инициативы, представленной для получения комментариев: отсутствие какой-либо конкретики относительно предлагаемых мер в высшей степени нехарактерно для ЕС и свидетельствует о крайней спешке, при которой в жертву срокам приносятся многолетние традиции ЕС по подробной и обстоятельной проработке любых вопросов. В качестве весьма общих мер в рамках ПКУМ Еврокомиссия обозначила следующие:

- введение НДС для всех товаров, реализуемых в ЕС (данный налог будет распространяться как на зарубежных, так и на внутренних производителей);

- введение пограничного налога на импорт отдельных углеродоемких видов продукции (его размер будет зависеть от стоимости выбросов СО2 в рамках европейской системы торговли квотами на выбросы парниковых газов);

- распространение действия Европейской системы торговли выбросами (EU ETS) на «углеродный след» импортных товаров; в этом случае их экспортерам/ производителям придется приобретать европейские разрешения на выбросы (EU Allowances (EUA).

В пояснительной записке указывается, что соответствующие меры будут разработаны позже в деталях, чтобы соответствовать правилам ВТО. Несмотря на общий характер предложений и сжатые сроки представления комментариев, заинтересованные стороны проявили высокую активность и представили немало заслуживающих внимания соображений. Самые значительные из них сводятся к следующему:

- трансграничный углеродный налог ЕС должен рассматриваться как крайняя мера и лишь после того, как будут исчерпаны другие способы защиты конкурентных интересов ЕС такие, например, как экологические стандарты;

- если такой механизм будет введен, его применение должно быть основано исключительно на точной оценке выбросов углерода при производстве всех видов 
продукции с раскрытием полной информации об источниках их происхождения; налогообложение при этом должно принимать во внимание параметры содержания углерода в ходе и первичного производства, и процессов переработки, включая как прямые, так и косвенные выбросы СО2;

- должна быть проведена оценка того, получит ли соответствующий механизм признание со стороны других государств;

- важно провести оценку того, как такой механизм отразится на потребителях, и будет ли на них переложено бремя увеличения цен;

- ЕС должен учитывать, что именно развитые страны исчерпали основной углеродный бюджет, что создает некий «климатический долг» перед развивающимися государствами; кроме того, он должен принимать во внимание действующие двухсторонние торговые соглашения;

- в соответствии с правилами ВТО и Генерального соглашения по тарифам и торговле, вводимые налоги должны применяться равным образом к внутренним и импортируемым продуктам, и не могут создавать необоснованные дополнительные обременения для зарубежных производителей;

- в случае введения данного налогового механизма ЕС должен предусмотреть возможность полного или частичного освобождения от его действия производителей в тех странах, которые применяют аналогичные механизмы; с другой стороны, выборочное освобождение таких государств не соответствует закрепленному правилами ВТО правовому принципу режима наибольшего благоприятствования;

- указанный налоговый механизм не учитывает тот факт, что страны имеют дифференцированные обязательства в рамках Парижского соглашения в зависимости от уровня их экономического развития;

- использование данного механизма может, по сути, рассматриваться как санкция для государств, не вводящих аналогичных мер на национальном уровне;

- даже если допустить, что вводимые меры будут соответствовать правилам ВТО, их сложно корректно оформить с методологической точки зрения, в том числе, в плане оценки выбросов всех парниковых газов при производстве импортной продукции в форме эквивалентной стоимости $\mathrm{CO} 2$;

- введение механизма требует системного пересмотра соответствующих нормативноправовых актов в области регулирования и налогообложения;

- необходимо будет учитывать связь с Европейской системой торговли выбросами, при этом ЕС должен будет прекратить выдачу свободных (бесплатных) квот промышленным предприятиям;

- в отсутствие диалога с международными партнерами данная инициатива может стать причиной новых внешнеторговых конфликтов.

Обилие замечаний и необходимость вместе с введением пограничного налога существенной перестройки не только налоговой системы стран ЕС, но и изменения соответствующих международных соглашений дает основание утверждать о нецелесообразности внедрения ПКУМ. Тем не менее, общий настрой Еврокомиссии не позволяет рассчитывать на то, что ЕС откажется от этого проекта. 


\section{Оценка рисков}

ПКУМ является инициативой не только сомнительной с правовой точки зрения, но и несущей немалые риски для российских экспортеров, для которых ЕС - главный партнер (39,5\% российского товарооборота за 1-е полугодие 2020 г. приходится на Евросоюз). Однако точная количественная оценка рисков, связанных с пограничным налогом, представляется затруднительной. Причина этого - в наличии ряда существенных неопределенностей, делающих невозможным точный расчет. К важнейшим параметрам, которые не определены, можно отнести следующие.

1. В части налогооблагаемой базы.

- Отсутствие четкого представления о том, какие виды импортируемой продукции будут включены в ПКУМ. Пока обсуждают вопрос о включении таких отраслей как черная и цветная металлургия, химия, цементная промышленность, нефтепереработка, минеральные удобрения, электроэнергия. От того, что из этого списка конкретно будет включено, зависит объем потенциальных финансовых потерь российских экспортеров.

- Неясность в подходе относительно типа «углеродного следа», подлежащего налогообложению: он может рассчитываться как по объему выбросов только на предприятии-производителе (прямые выбросы), так и по объему выбросов по всему циклу создания продукта (полный углеродный след, включающий прямые и косвенные выбросы). Последняя опция не только создает технические трудности как при собственно расчете, так и при верификации, но увеличивает также финансовую нагрузку на экспортеров. Кроме того, рассматривается опция взимания налога на разницу между углеродоемкостью экспортируемой продукции и нормативом, установленным в ЕС (так называемым бенчмарком).

- Слабая готовность методической базы для расчетов «углеродного следа» по многим видам импортируемой продукции; по оценкам европейских экспертов, разработка полного пакета методологий по всем видам подлежащей налогообложению продукции может занять нескольких лет.

\section{2. В части предполагаемых ставок налога.}

- Ставки пограничного налога предполагаются на уровне цен на европейские разрешения на выбросы (EUA) в рамках системы торговли EU ETS. Цены на EUA в последние годы варьировались в диапазоне 25-30 евро за тонну эквивалента СО2, прогнозный диапазон эксперты оценивают в широком коридоре (25-50 евро за тонну), что само по себе создает большую степень неопределенности. Например, по оценке Bloomberg, ставка EUA в 2023 г. предполагается на уровне 40,9 евро.

- Этот ценовой прогноз в основном отражал ситуацию на стадии разработки ПКУМ (2019 г.), когда была актуальна цель ЕС по 40\%-ному сокращению выбросов. Ужесточение цели до 55\% и, тем более, до 60\% при весьма скромном потенциале предприятий ЕС, на многих из которых технические возможности по сокращению выбросов уже исчерпаны, может вызвать ажиотажный спрос на EUA. До какого уровня такая ситуация может повысить цены, остается неясным. 
В условиях подобной неопределенности единственным методом проведения экспертных оценок рисков является сценарный метод. В частности, в исследовании, представленном недавно аудиторской компанией KPMG, был использован метод укрупненных и упрощенных сценариев, впрочем, не отражающих влияния всех факторов. Сценарии, разработанные таким методом, могут использоваться в качестве первого приближения. Они включают следующие.

- Пессимистический сценарий, предполагающий обложение прямых и косвенных выбросов в 2022 г.

- Базовый сценарий: обложение прямых выбросов в 2025 г.

- Оптимистический сценарий: обложение разницы между углеродоемкостью, импортируемой продукции, и бенчмарком ЕС в 2028 г.

Во всех сценариях прогнозируется цена на сокращения в EU ETS на уровне от 25 до 50 евро за тонну эквивалента СО2 в период 2020-2030 гг. Проделанный на основе этих прогнозов итоговый расчет показывает следующие финансовые потери российских корпораций в период до 2030 г.:

- по пессимистическому сценарию - 50,6 млрд. евро;

- по базовому сценарию - 33,3 млрд. евро;

- по оптимистическому сценарию - 6,0 млрд. евро.

Несмотря на такой разброс в оценках, очевиден вывод: по масштабам финансовых рисков для России ПКУМ превосходит антидемпинговые меры, предпринятые ранее Евросоюзом против России. Более того, по прогнозам той же KPMG, среди торговых партнеров ЕС именно Россия понесёт наибольшие потери от пограничного налога. Ежегодные потери нашей страны превысят потери Китая по пессимистическому сценарию в 4,1 раза, по базовому сценарию - в 4,6 раза, а по оптимистическому сценарию - в 8,5 раза. Многократно превысят потери России по отношению к соответствующим издержкам США: по пессимистическому сценарию - в 3,5 раза, по базовому сценарию - в 4,5 раза, а по оптимистическому сценарию - в 10 раз. Объясняется это разницей в товарной структуре российского экспорта, в котором преобладают сырье и продукция первого передела, а в случае США и Китая - товары с высокой долей добавленной стоимости.

Надо отметить, что продукция первого передела намного более чувствительна к подобному налогообложению, чем высокотехнологичные изделия. Например, если выбросы СО2 при производстве 1 тонны чугуна составляют 1,5 тонны, то при экспортной цене порядка 230 евро за тонну налог может составить до 75-100 евро, что повысит цену на 33-45\%. Если же речь идет о продукции машиностроения, то аналогичный налог повышает цену в среднем не более чем на $1 \%$. Иными словами, для высокотехнологичной продукции новый налог практически неощутим, тогда как для продукции первого передела прибавка к цене может сделать этот вид товаров совершенно неконкурентоспособным на рынке ЕC, что фактически позиционирует ПКУМ как меру, направленную на подрыв экспортных возможностей именно нашей страны. 


\section{Политические меры противодействия}

Предвидя негативное отношение к своей инициативе, ЕС выбрал специфическую тактику ее продвижения в мировом сообществе: с каждым значимым глобальным игроком ведется своя, отдельная линия переговоров, с учетом уязвимости соответствующего партнера и особенностей его интересов. Особенная активность проявляется в отношении Китая. Что же касается США, здесь ЕС в основном рассчитывает на благоприятный для него исход президентских выборов. Не случайно даже сроки окончания консультаций по ПКУМ Евросоюз наметил на 28 октября 2020 г., «подогнав» их впритык к дате выборов в США. К этой дате предполагали закончить дискуссии внутри ЕС и выйти на переговоры с США с согласованной позицией.

Основным форматом двусторонних консультаций с торговыми партнерами на неофициальном (полуофициальном) уровне является Европейский круглый стол по изменению климата и устойчивому переходу (European Roundtable on Climate Change and Sustainable Transition (ERCST). За последние два месяца ERCST провел серию вебинаров по обмену мнениями с представителями США, Индии, России, Южной Кореи, Японии, Украины, Южной Африки и Мексики.

Бросается в глаза отсутствие в этом списке Китая, работа с которым ведется непосредственно в Пекине по линии так называемого «специального экологического проекта ЕС-Китай», руководитель которого Димитри де Бур не скрывает, что именно признание ПКУМ Китаем является его главной задачей, но отмечает трудности её выполнения.

Опасения в связи с введением ПКУМ, видимо, заставит некоторые страны пойти на использование внутреннего углеродного налога, который самый негативным образом отразится именно на энергоемких отраслях, что вполне вписывается в стратегию ЕС по сохранению и развитию собственных энергоемких отраслей и повышению уровня самообеспеченности всеми видами продукции.

Особую тревогу у ЕС вызывает перспектива объединения ведущих стран против инициативы ПКУМ, что чревато повторением ситуации 2012 г., когда ЕС вознамерился брать плату за загрязнение атмосферы над его территорией авиационными выбросами. Чтобы не допустить такого развития событий, Евросоюз работает над разобщением оппонентов, делая некоторым из них заманчивые авансы. Помимо адресованной Китаю идеи сокращения расходов на ПКУМ при введении «домашнего» китайского углеродного налога, этой же стране предлагаются и иные льготы, например, полное исключение из ПКУМ всех видов машин, оборудования и других высокотехнологичных товаров (идея, очевидно, рассчитана и на США). Появляются даже советы исключить из ПКУМ продукцию металлургии - потому, что она занимает важное место в китайском экспорте. По позициям, актуальным именно для российского экспорта, никаких предложений по льготам пока не поступало.

Что касается официальных переговоров между ЕС и Россией, то, на наш взгляд, не следует думать, что ЕС пойдёт на какие-либо значительные уступки. Скорее всего, он 
займёт жесткую позицию. Аппарат Еврокомиссии традиционно настроен негативно по отношению к интересам России. Попытки изменить это отношение на уровне двусторонних переговоров в формате «Россия-ЕС» с большой вероятностью успеха не принесут, хотя, безусловно, отказываться от переговоров было бы неправильно: они позволят выявить весь комплекс аргументов противной стороны, к разработке которых привлечены лучшие эксперты ЕС и соответствующее масштабное финансирование. Подобные переговоры и консультации, кроме того, способствуют выработке российской аргументации по защите российских интересов.

Как нам кажется, аргументы России против ввода пограничного налога могут состоять в следующем.

1. ПКУМ противоречит Рамочной Конвенции ООН об изменении климата (РКИК $\mathrm{OOH})$. Согласно статье 3 части 5 Конвенции, не допускается использование мер по борьбе с изменением климата для дискриминации отдельных стран.

2. Он противоречит также некоторым положениям Парижского соглашения по климату, в которых говорится об усилиях стран в области защиты климата на основе «...общей, но дифференцированной ответственности и соответствующих возможностей государств, в свете различных национальных условий» (преамбула и ст. 4 п.3).

3. ПКУМ не соответствует целям, сформулированным в ст. 4 п. 15 Парижского соглашения, в котором выражается обеспокоенность проблемами стран, экономика которых наиболее пострадала от выполнения обязательств в соответствии с этим соглашением по защите окружающей среды.

4. ПКУМ противоречит положениям п. 1 ст. ХІ ГАТТ 1947 г. и правилам ВТО, которые не допускают дискриминацию ввозимых товаров по сравнению с товарами отечественного происхождения, а также использование скрытых ограничений в международной торговле.

Чтобы противодействовать внедрению пограничного налога, важно также опираться на опыт разрешения споров между ЕС и другими странами по поводу внедрения последним в 2012 г. «углеродного сбора» для иностранных авиакомпаний, совершающих рейсы в Евросоюз. Этот опыт показывает, что эффективная тактика координация действий стран - потенциальных плательщиков налога (Китая, России, США и др.). Полезную роль сыграло также вынесение проблемы для обсуждения на глобальную площадку, в Международную Организацию Гражданской Авиации (ИКАО).

Для противодействия новой налоговой инициативе такой площадкой могла бы стать $\mathrm{OOH}$, более конкретно - Организация Объединенных Наций по Промышленному Развитию (ЮНИДО) или Конференция Объединенных Наций по Торговле и Развитию (ЮНКТАД). Профиль обоих организаций которой полностью соответствует проблеме, что дает возможность её квалифицированного обсуждения, с привлечением всех стран - потенциальных плательщиков налога.

Конечно, этим не исчерпываются возможные форматы координации действий России со странами, озабоченными перспективой введения ПКУМ. Здесь должны быть задействованы и такие объединения как Шанхайская Организация Сотрудничества (ШОС), БРИКС, СНГ, Евразийский экономический союз (ЕАЭС) и Союзное 
государство РФ и Белоруссии. На всех этих площадках должны быть развернуты дискуссии с участием ведущих экспертов соответствующих стран. Учитывая то, что ПКУМ может самым непосредственным образом отразиться на экономическом развитии соответствующих стран, к работе должны быть привлечены соответствующие институты развития, включая Новый Банк Развития БРИКС и Евразийский Банк Развития.

Кроме этого, в работе необходимо участие организаций бизнес-сообщества соответствующих стран, включая Деловой совет БРИКС, Деловой совет ШОС, Деловой совет ЕАЭС, Деловой Центр экономического развития СНГ, Российско-Белорусский деловой совет. Эти структуры следует ориентировать на выработку общей позиции делового сообщества и формирование рекомендаций правительствам, направленных на хеджирование рисков, связанных с ПКУМ.

Результатом общей согласованной работы должно стать выработка международной оценки инициативы ЕС и разработка альтернативных предложений, и инициатив и мер противодействия, направленных противодействие ПКУМ с целью его отмены или как минимум ощутимо смягчающих эффект от его применения. Развертывание этой работы потребует предельной оперативности и качественной координации, что обусловлено жесткими сроками, отведенными ЕС на продвижение ПКУМ. Учитывая масштабы рисков России в связи с новым механизмом ЕС (ПКУМ), предлагаем поддержать инициативу о развертывании данной работы в кратчайшие сроки.

Дата выпуска: 10 декабря 2020 года.

Series of articles in journal «Analytical papers of the Institute of Europe RAS»

№44, 2020 (№227)

\title{
EU Carbon Border Adjustment Mechanism: status, risks and possible response
}

\begin{abstract}
Subject of the analysis is the EU initiative of introducing the Carbon Border Adjustment Mechanism, developed within the framework of the «European Green Deal» adopted in 2019. The authors analyze in detail the origin of European border carbon tax initiatives, draw a parallel between the Carbon Border Adjustment Mechanism and the early EU initiatives on carbon taxation of flights of foreign airlines to airports in the EU countries. The article describes the tactics used by the European Union to develop the details of the proposed mechanism and to promote it on the international arena. Particular attention is paid to the assessment of the risks of Russian export-oriented sectors in case of introduction of the Carbon Border Adjustment Mechanism and possible responses from the Russian side.
\end{abstract}

Keywords: Carbon Border Adjustment Mechanism, European Green Deal, carbon leakage, greenhouse gas emissions, Paris Agreement, European emissions trading system, CORSIA system, climate neutrality, regenerative growth strategy, EU Next Generation EU Recovery Plan, carbon footprint of imported goods, EU Allowances (European greenhouse gas permits), carbon budget, WTO, General Agreement on Tariffs and Trade.

DOI: http://doi.org/10.15211/analytics442020 


\section{http://www.zapiski-ieran.ru}

Release date: December 10, 2020. 